\title{
Chemical-Specific Representation of Air-Soil Exchange and Soil Penetration in Regional Multimedia Models
}

\author{
T.E. McKone ${ }^{1,2, *}$ and D.H. Bennett ${ }^{3}$
}

May 2002

\author{
${ }^{1}$ Lawrence Berkeley National Laboratory, Berkeley, CA \\ ${ }^{2}$ School of Public Health, University of California, Berkeley CA \\ ${ }^{3}$ Harvard School of Public Health, Boston MA \\ *Corresponding Author \\ Lawrence Berkeley National Laboratory \\ 1 Cyclotron Road, 90-3058 \\ Berkeley CA, 94720 \\ Phone 510-486-6163 \\ Fax 510-486-6658 \\ email TEMcKone@LBL.gov
}




\section{ABSTRACT}

In multimedia mass-balance models, the soil compartment is an important sink as well as a conduit for transfers to vegetation and shallow groundwater. Here a novel approach for constructing soil transport algorithms for multimedia fate models is

developed and evaluated. The resulting algorithms account for diffusion in gas and liquid components; advection in gas, liquid, or solid phases; and multiple transformation processes. They also provids an explicit quantification of the characteristic soil penetration depth. We construct a compartment model using three and four soil layers to replicate with high reliability the flux and mass distribution obtained from the exact analytical solution describing the transient dispersion, advection, and transformation of chemicals in soil with fixed properties and boundary conditions. Unlike the analytical solution, which requires fixed boundary conditions, the soil compartment algorithms can be dynamically linked to other compartments (air, vegetation, ground water, surface water) in multimedia fate models. We demonstrate and evaluate the performance of the algorithms in a model with applications to benzene, benzo(a)pyrene, MTBE, TCDD, and tritium. 


\section{INTRODUCTION}

Quantifying the mass transport of chemicals in soil and between soils and the atmosphere is important for characterizing the health and environmental impacts from contaminated soil and for understanding the role soil plays in controlling fate, transport, and exposure to airborne, multimedia pollutants. Mass-conservative "Mackay-type" multimedia compartment models have been used to assess the fate and transport of chemicals among air, soil, water, biota, and sediment compartments (1-4). The various media are represented as individually well mixed compartments. These models are most appropriate for treating transport and transformation of chemicals emanating from non-point sources over relatively long time and length scales at low concentrations (3). The flexibility and transparency of these models have made them important tools for decision makers to assess the potential for exposure and risk to humans and ecosystems (5-8). In contrast to multimedia models, relatively detailed single-domain transport and transformation models have been developed to model aspects of chemical transport and transformation within the vadose zone as a single medium or domain (9-13). Single-domain models are generally appropriate for smaller length and time scales, and typically do not consider transport between different domains, such as from surface soil to atmosphere.

Among existing multimedia models there are significant variations in both the complexity and structure applied to the soil compartment. Variations include how many types of soils are considered, how many layers are assumed in each soil type, and how the depth of the soil compartment is selected. Because experimental and theoretical evidence shows a large variation in the depth to which different chemicals penetrate, multimedia-model developers have acknowledged that each chemical requires a different soil depth to scale its transport into soil (3). But there is 
also a need for consensus on the most effective way to model the complex interactions in soil as they relate to exchange with other environmental compartments. In multimedia models, the air and soil are fully coupled so that chemical storage and transport can be represented simultaneously. Capturing the magnitude of chemical transport between air and soil is as important or (in some cases) more important than capturing the concentration profile within the soil (3). Recent examples include Pankow et al. (14), who considered the link between the urban atmosphere and soil layers to assess transport of MTBE into shallow groundwater and the work of other researchers to address the role of air/soil exchange in assessments of persistence and spatial range (15-17). Emerging spatially resolved models such as the urban-scale multimedia model of Premier and Diamond (18), the regional multimedia model TRIM (19), and the continental-scale BETR model (8) also require simple but reliable mass-exchange algorithms between the air compartment and soil. But there are no widely accepted algorithms that are fully calibrated with either data or with exact analytical or numerical solutions.

We propose an approach for soil mass transport that uses multiple soil compartments while maintaining a structure that links easily to other compartments (that is air, vegetation, etc.) in a multimedia model. The dynamic mass-balance differential equations include the diffusion in air and water phases of soil, advection via water, bioturbation, and chemical transformation. The solution to the differential equations is used to develop an equivalent compartment model representation that replaces concentration gradients by compartment-based inventories and transfer factors. The replacement is achieved by matching the fugacity and flux at the boundary between each pair of soil compartments with those from the solution of differential equations. We define the most appropriate soil layer structure for a given chemical and develop transfer factors that define mass flows based on the mass inventory of chemical in each compartment. 


\section{METHODS}

Our methods include a definition of the modeling problem, analytical solution of the one-dimensional convective-dispersive solute transport equation, derivation of the soil penetration depth from this solution, and development of the equivalent compartment model using multiple compartments and a variable soil penetration depth. Compartment models for soil columns that are compatible with existing multimedia fate models must account for air-soil exchange, storage and transformation in soil, and in some cases transport to shallow ground water $(2,4,8$, 27-29). While there are a number of mathematical algorithms $(9,11,22,25,26)$ available to solve the differential equations describing the transport and transformation of pollutants within soil, multimedia models rarely require this level of detail. Rather, the compartment model must be calibrated with steady-state and transient analytical solutions for mass exchange and storage.

Chemicals move through soil by advection in the liquid phase due to hydrological flow, diffusion in the gas phase and to some extent the liquid phase, bioturbation, and erosion near the soil surface (20-24). The thermodynamically driven partitioning of chemicals among the components of soils (gas, liquid, mineral, and organic) strongly impacts the rates of transport and transformation in and among soil compartments. Also affecting the rate of transport and transformation are climate and landform properties, which include temperatures of air and soil, rainfall rates, soil properties (bulk density, porosity), and variability of these properties within soil.

\section{Soil Compartments in Multimedia Models}

Many fugacity models $(1,4)$ use one or more well-mixed soil compartments with uniform vertical concentrations and chemical distribution among the liquid, solid, and organic phases of soils according to equilibrium partitioning. Compartments with homogenous composition and bulk mixing make the mass- 
balance equations relatively easy to assemble and solve. Because of the heterogeneity of soils and the likelihood of larger vertical concentration gradients, it is more difficult to impose these conditions on soil compartments than on compartments such as air or surface water. In current models, the depth of the soil compartment is often assigned a fixed value based on a generic penetration depths such as the plowing depth or the depth to which bioturbation is expected to evenly mix soil $(1,5,8,15,27)$. There have also been efforts to define chemical-specific layers in soil. Jury et al.(30) determined that all but the most volatile contaminants can be characterized by the thickness of soil that makes diffusion unlikely as a loss pathway. Cowan et al. (3) recognized that various chemicals are likely to penetrate to different depths in soil, and described the use of the overall Damkoehler number ( $N_{\mathrm{DA}}$ as discussed below) to establish how far a chemical is likely to partition into soil from the atmosphere.

Some models have employed a layered structure. For example a three layer structure consisting of surface soil $(0$ to $0.1 \mathrm{~cm})$, intermediate soil $(0.1$ to $25 \mathrm{~cm})$, and deep soil $(>25 \mathrm{~cm})$ first used in the PATHWAY model for evaluating radioactive fall-out on a regional scale (31). The CalTOX model uses a similar three-layer structure with soil transport parameters obtained empirically by matching compartment inventories to those obtained from the analytical solution by Jury et al. (32). The use of finite difference algorithms to model transport in soil results in a large number of soil layers that must be matched up to the remaining non-spatial compartments (air, soil vegetation, etc.,) (29). While reducing some of the potential numerical error, the "brute force" nature of this approach substantially increases the number of compartments that must be parameterized and managed in the multimedia simulation. 
Analytical Solution of Convective-Disperisve Solute Transport and the Damkoehler Depth

The governing equation for mass balance within any specified region of the soil column is given by $(9,33)$

$$
\frac{\partial C}{\partial \mathrm{t}}=\frac{\partial}{z}\left\lceil D_{\mathrm{e}} \frac{\partial C}{\partial \mathrm{z}}\right\rfloor-v_{\mathrm{e}} \frac{\partial C}{\partial z}-k C
$$

where $C$ represents the bulk chemical concentration in soil, mol(chemical) $\mathrm{m}^{-3}$ (soil); $t$ is time, $\mathrm{s} ; z$ is depth in a soil column measured from the top surface, $\mathrm{m} ; C_{0}$ is the bulk concentration at the soil surface, $\mathrm{mol} \mathrm{m}^{-3} ; k$ is the transformation rate, $1 \mathrm{~s}^{-1} ; D_{e}$ is the bulk diffusion coefficient in the soil, $\mathrm{m}^{2} \mathrm{~s}^{-1}$; and $v_{\mathrm{e}}$ is the bulk advection velocity of the chemical in the soil, $\mathrm{m} \mathrm{s}^{-1}$. Jury et al have solved this for the condition of initial soil contamination in a defined region, but air concentration at zero. We are interested in the situation in which the soil is being contaminated by the atmosphere, that is an air compartment with higher fugacity than soil. For this the appropriate boundary conditions are:

$$
\begin{aligned}
& C(z=0, t)=C(0) \\
& C(z>0, t=0)=0 \\
& C(z \rightarrow \infty, t>0) \rightarrow 0
\end{aligned}
$$

When $\mathrm{v}_{\mathrm{e}}, \mathrm{D}_{\mathrm{e}}$, and $\mathrm{k}$ are constant in time, the solution to Eq. (2) with the boundary conditions above has be been published (33) as

$$
\begin{gathered}
C(z, t)=C_{0}\left\{\frac{1}{2} \exp \left[\frac{\left(v_{e}-u\right) z}{2 D_{e}}\right] \times \operatorname{erf}\left[\frac{(z-u t)}{2 \sqrt{D_{e} t}}\right]+\frac{1}{2} \exp \left[\frac{\left(v_{e}+u\right) z}{2 D_{e}}\right] \times \operatorname{erf}\left[\frac{(z+u t)}{2 \sqrt{D_{e} t}}\right]\right\} \\
\text { where } u=\sqrt{v_{e}^{2}+4 k D_{e}}
\end{gathered}
$$


Eq. 1 uses concentration as the state variable, but can easily be converted to fugacity-based equations using the relationship $C=f Z$, where $f$ is the chemical fugacity in soil, $\mathrm{Pa}$, and $\mathrm{Z}$ is the bulk-soil fugacity capacity, $\mathrm{mol} /\left(\mathrm{m}^{3}-\mathrm{Pa}\right)(4)$. We determine the effective bulk diffusion coefficient resulting from vapor and waterphase tortuous diffusion following the approach of Jury et al. $(9,34)$. An alternative approach for representing soil gas diffusion has been described Moldrup et al. (35). We add to the bulk diffusion coefficient a term to represent the bioturbation dispersion, accounting for worms and other detritivores that consume soil as well as burrowing creatures such as ants whose tunneling moves soil and increases the spread of chemicals in soil $(20,23)$. Our resulting bulk-soil effective diffusivity, $D_{\mathrm{e}, i}$ in $\mathrm{m}^{2} \mathrm{~s}^{-1}$, for each soil layer, $\mathrm{i}$, takes the form:

$$
D_{\mathrm{e}, i}=\frac{Z_{\text {air }}}{Z_{i}}\left(\alpha_{i}^{10 / 3} / \varphi_{i}^{2}\right) D_{\mathrm{a}}+\frac{Z_{\text {water }}}{Z_{i}}\left(\beta_{i}^{10 / 3} / \phi_{i}^{2}\right) D_{\mathrm{W}}+D_{\text {bio, } \mathrm{i}}
$$

where $Z_{x}$ represents the fugacity capacity of either a pure phase ( $x=\mathrm{a}$ for air and $x=\mathrm{w}$ for water) or of a bulk phase ( $x=i$ for the $i$ th soil layer in multi-layered system), $\mathrm{mol} /\left(\mathrm{m}^{3}-\mathrm{Pa}\right) ; \alpha_{i}$ is the volume fraction of soil occupied by gas in layer $\mathrm{i}$, no units; $\beta_{i}$ is the volume fraction occupied by gas in layer $i$, no units; $\phi_{i}$ is the total void fraction of the bulk soil in layer $\mathrm{i}\left(\alpha_{i}+\beta_{i}\right)$, no units; $D_{x}$ is the diffusion coefficient of the chemical in a pure fluid ( $\mathrm{x}=\mathrm{a}$ for air and $\mathrm{w}$ for water), $\mathrm{m}^{2} \mathrm{~s}^{-1}$; and $D_{\mathrm{bio}, \mathrm{i}}$ is the diffusion coefficient accounting for bioturbation in layer $\mathrm{i}, \mathrm{m}^{2} \mathrm{~s}^{-1}$. We obtain bioturbation diffusivity values from Cousins et al. $(24,36)$.

The effective advection velocity, $v_{\mathrm{e}, i}$ in $\mathrm{m} \mathrm{s}^{-1}$, of contaminant resulting from the flux of water induced by net rain-fall or irrigation infiltration is based on partitioning of the chemical to the mobile phase relative to the bulk inventory,

$$
v_{\mathrm{e}, \mathrm{i}}=v_{\text {water }, \mathrm{i}} \frac{Z_{\text {water }}}{Z_{i}}
$$


where $v_{\text {water, }}$ is the flux of water through the soil, $\mathrm{m} \mathrm{s}^{-1}$.

Under steady-state conditions and with a fixed concentration boundary condition, Eq. 2 simplifies to,

$$
C(z)=C(0) e^{-\gamma_{i} z}
$$

and describes the vertical gradient of concentration in a soil layer where

$$
\gamma_{i}=\sqrt{\left[\left(\frac{v_{e, i}}{2 D_{e, i}}\right)^{2}+\frac{k_{i}}{D_{e, i}}\right\rfloor}-\frac{v_{e, i}}{2 \cdot D_{e, i}} \quad \text { or, if } v_{e, i}=0, \quad \gamma_{i}=\sqrt{\frac{k_{i}}{D_{e, i}}}
$$

The Damkoehler number $\left(N_{\mathrm{DA}}\right)$ expresses the ratio of chemical transformation loss to diffusion and advection loss and is defined as

$$
N_{\mathrm{DA}}=\frac{C \times k \times z}{C \times\left(v_{e}+D_{e} / z\right)}
$$

In a vertical soil profile with a fixed surface concentration, a unit value of $\mathrm{N}_{\mathrm{DA}}$ corresponds to the depth, $z$, at which soil concentration decreases by 1 /e relative to the surface concentration. We refer to this depth as $\mathrm{z}^{*}$ and use it to normalize the scale for mass transfer in soils.

$$
z^{*}=1 / \gamma,=\sqrt{\frac{D_{e}}{k}}, \text { if } \mathrm{v}_{\mathrm{e}}=0, \text { else }=\frac{v+\sqrt{v^{2}+4 k D_{e}}}{2 \cdot k}
$$

Figure 1 illustrates how Eq. 2 simplifies to Eq. 5 as the normalized time $t / \mathrm{t}^{*}$ approaches infinity, where, 


$$
t^{*}=\frac{4 D_{e}}{\left(v_{e}^{2}+4 D_{e} k\right)}
$$

\section{Compartment Model Formulation}

Soils are heterogeneous and can be comprised of horizontal layers with different composition. In Figure 2, we illustrate typical soil layers as found in the environment along with the model representation we use to aggregate this structure in a compartment model. When constructing a multi-compartment model for vertical transport, we select three layers to characterized the different vertical horizons--ground surface soil, root zone soil, and vadose zone soil. The thin ground surface layer of soil interacts closely with the air compartment. We find this layer necessary to accurately represent mass transfer between atmosphere and soil. Studies of radioactive fallout in agricultural land-management units (31) reveal that, in the absence of tilling, particles deposited from the atmosphere accumulate in and are resuspended from a thin, 0.1 to $1 \mathrm{~cm}$, surface-soil layer. Here contaminants are susceptible to wind erosion, water erosion and runoff, volatilization, photolysis, biodegradation, transfer to plant surfaces by rainsplash, and transport vertically to and from the root-zone soil by diffusion and leaching (22). The root-zone soil contains the roots of plants, extends to about one meter in depth (37), and has high organic matter and water content relative to deeper soil (38). Here contaminants are transported upward by diffusion, volatilization, root uptake, bioturbation, and capillary motion of water; transported downward by diffusion, leaching and bioturbation; and transformed chemically primarily by biodegradation or hydrolysis $(20,22-24,39)$. Below the root zone is the vadose zone, characterized by lower organic matter content and biologic activity. Contaminants in this layer move upward to root soil and downward to the ground-water zone primarily by capillary motion of water, leaching and bioturbation. Chemical transformation in this layer 
is primarily by biodegradation. We use these regions as guidelines to establish chemical and physical properties, but we use chemical-specific penetration depths to scale the soil compartments for mass transfer estimates.

We illustrate the application of a vertical compartment structure with air and three soil compartments, but any number of environmental compartments and soil layers can be employed in this scheme. We apply mass balance by defining the inventory in each vertical compartment $i$, as $N_{i}$ the state variable (mol), and transfer factors, $T_{i j}\left(\mathrm{~s}^{-1}\right)$ that account for the rate of transfer between each $i$ and $j$ compartment pair. Under steady-state conditions, the mass balance for the air compartment and three soil-layer compartments give rise to the following set of mass balance equations:

$$
\begin{array}{lr}
\left(T_{a g}+k_{a}\right) N_{a}=S_{a}+T_{g a} N_{g} & \text { \{AIR\} } \\
\left(T_{g a}+T_{g s}+k_{g}\right) N_{g}=T_{a g} N_{a}+T_{s g} N_{s} & \text { \{Ground-surface SOIL\} } \\
\left(T_{s g}+T_{s v}+k_{s}\right) N_{s}=T_{g s} N_{g}+T_{v s} N_{v} & \text { \{Root-zone SOIL\} } \\
\left(T_{v s}+k_{v}\right) N_{v}=T_{s v} N_{s} &
\end{array}
$$

where the compartment subscripts used are $a$ for air, $g$ for ground-surface soil, $s$ for root-zone zone soil and $v$ for deeper vadose-zone soil and $S_{a}$ represents the source term to air, mol s-1. Eqs. 10 through 13 are easily solved to find the inventories $N_{i}$, which can be converted to either an equivalent fugacity or bulk concentration based on compartment volume and fugacity capacity. 
Matching Compartment Inventory, Fugacity, and Mass Balance to the Analytical Model

In order to define " $\mathrm{T}$ " factors in Eqs. 10 through 13, we match the inventory in each soil compartment and the mass flow and fugacity at the boundary between

compartments obtained from this set of equations to results obtained from Eq. 5. The key step in this effort is establishing relationship between the air concentration and the concentration in first soil layer. This step establishes the boundary condition for the surface soil as well as all deeper soil layers.

The mass flow across the air-soil interface is determined by a two-resistance mass-transfer model, defined by the resistance in a thin boundary layer of air over the soil surface, the difference in the gas phase fugacity across the boundary, and the resistance through the thin surface soil layer, as well as advective processes, such as rainfall and particle deposition. We use the following expression to account for the mass balance among these processes $(28,32)$.

Flow $=$ Areax $\left[\left(C_{a}-\frac{Z_{a i r}}{Z_{g}} C_{g}\right)\left(\frac{1}{U_{a}}+\frac{Z_{a}}{Z_{g} U_{g}}\right)^{-1}+\left(V_{d} \frac{P C \times Z_{a p}}{\rho_{a p} Z_{a}}+\right.\right.$ rain $\left.\left.\frac{Z_{\text {water }}}{Z_{a}}\right) C_{a}\right\rfloor$

In this expression, Flow is the flow of contaminant between air and surface soil, $\mathrm{mol} \mathrm{s}^{-1}$; Area is the horizontal area of contact between two compartments, $\mathrm{m}^{2} ; C_{\mathrm{a}}$ is the bulk contaminant concentration in the air compartment, $\mathrm{mol} / \mathrm{m}^{3}$; and $C_{\mathrm{g}}$ is the bulk contaminant concentration in the surface soil compartment, $\mathrm{mol} / \mathrm{m}^{3}$. Table 1 provides definitions of the fugacity capacities $Z_{\mathrm{air}}, Z_{\mathrm{g}}$ and $Z_{\mathrm{a}}$ obtained from Mackay (4) and $Z_{\text {ap }}$ from Harner et al. (40). Table 2 provides values for the landscape parameters $V_{d}, P C, \rho_{\mathrm{ap}}$, and rain. $U_{\mathrm{a}}$ and $U_{\mathrm{g}}$ are the mass-transfer coefficients on, respectively, the air side (a) and the soil side (g) of the air-soil interface, $\mathrm{m} \mathrm{s}^{-1}$, which are determined from standard methods $(1,9,28,32,41)$, 


$$
\begin{gathered}
U_{a}=\frac{D_{a i r}}{\delta_{a g}} \\
U_{g}=\frac{D_{e, g}}{0.5 \times d_{g}}
\end{gathered}
$$

where $D_{\text {air }}$ as the contaminant diffusion coefficient in pure air, $\mathrm{m}^{2} \mathrm{~s}^{-1}, \delta_{\mathrm{a}}$ the thickness of equivalent diffusion boundary layer in the air above the soil, $\mathrm{m} ; D_{\mathrm{e}, \mathrm{g}}$ is the equivalent bulk diffusion coefficient in the ground-surface soil layer, $\mathrm{m}^{2} \mathrm{~s}^{-1}$; and $d_{\mathrm{g}}$ is the thickness of ground-surface soil layer. We simplify Eq. 15 by defining the fugacity-based mass-transfer coefficient at the air-soil interface, $Y_{\mathrm{ag}}, \mathrm{mol} /\left(\mathrm{m}^{2}-\mathrm{Pa}-\mathrm{s}\right)$,

$$
Y_{a g}=\left\lceil\frac{1}{Z_{a i r} U_{a}}+\frac{1}{Z_{g} U_{g}}\right\rceil^{1}
$$

and substituting the fugacities $f_{\mathrm{a}}$ and $f_{\mathrm{g}}(\mathrm{Pa})$ in the air and bulk ground surface soil layer, respectively, for $C_{a} / Z_{a}$ and $C_{g} / Z_{g}$ to obtain

$$
\text { Flow }=\operatorname{Area\times }\left[Y_{a g} \times\left(f_{a}-f_{g}\right)+\left(V_{d} \frac{P C \times Z_{a p}}{\rho_{a p}}+\text { rain } \times Z_{\text {water }}\right) f_{a}\right\rfloor
$$

By matching the net flow across the air-soil boundary from Eq 10, Flow = $T_{\mathrm{ag}} N_{\mathrm{a}}-T_{\mathrm{ga}} N_{\mathrm{g}}$, with the flow expressed in Eq 19, and substituting $N=f Z V$ we obtain the appropriate expressions for $T_{\mathrm{ag}}$ and $T_{\mathrm{ga}}$, which are provided in Table 3. Also listed in Table 3 are fugacity-based transfer factors, which are equal to $T_{i j} Z_{i} V_{i}$ and compatible with Mackay-type models (4), which use fugacity $f$ instead of inventory $N$ as the state variable. 
In the soil compartments below the ground-surface layer, we use the transport rates and concentration gradients from the steady state analytical solution of Eq. 1 to develop transfer factors that account for concentration gradients. The compartment inventory $N_{i}$ is equal to the integral of the concentration in layer $i$ and is a function of the soil surface concentration, $\mathrm{C}_{0}$.

$$
\begin{gathered}
N_{i}=\underset{0}{\operatorname{Area} \int_{i}} C_{i}(0) e^{-\gamma_{i} z} d z=\operatorname{Area} \frac{C_{i}(0)}{\gamma_{i}}\left(1-e^{-\gamma_{i} d_{i}}\right) \\
C_{i}(0)=C_{0} \times e^{-\gamma_{1} d_{1}} e^{-\gamma_{2} d_{2}} \ldots e^{-\gamma_{i-1} d_{i-1}}
\end{gathered}
$$

We then derive the corresponding $T$ factors by matching the diffusive and advective flow expressions from the compartment equations to flow obtained from the analytical solution. In the following paragraphs, we develop this approach first for the top two soil layers and then generalize to the transfer between any two nonsurface compartments. We assume each soil layer is homogeneous such that Eq. 5 defines the exponential concentration decrease with depth in each soil layer, but we allow differences in properties among soil layers.

First we consider the diffusive mass flow, Flow $_{D}$ in $\mathrm{mol} \mathrm{s}^{-1}$, between compartments $g$ and $s$. At the lower boundary $\left(\mathrm{z}=d_{\mathrm{g}}\right)$ of $g$ and at the upper boundary of compartment s we obtain,

$$
\begin{gathered}
\text { Floum }=- \text { Areax }\left.D_{e, g} \frac{d C}{d z}\right|_{z=d_{g}}=\operatorname{Area\times } D_{e, g} C_{g}(0) \gamma_{g} e^{-\gamma_{g} d_{g}} \\
\text { Flow }=-\left.\operatorname{Area\times } D_{e, s} \frac{d C}{d z}\right|_{z=0}=\operatorname{Area\times } D_{e, s} C_{s}(0) \gamma_{s}
\end{gathered}
$$


But from the compartment-model formulation we obtain for $\mathrm{Flow}_{D}$ the following:

$$
\text { Flow }=\text { Area } \cdot Y_{g S}\left(f_{g}-f_{s}\right)=\text { Area } \cdot Y_{g s}\left(\frac{N_{g}}{Z_{g} V_{g}}-\frac{N_{S}}{Z_{S} V_{s}}\right)
$$

where $Y_{\text {gs }}$ is the fugacity-based mass transfer coefficient between the two soil layers, $\mathrm{mol} /\left(\mathrm{m}^{2}\right.$-s-Pa). We use Eq. 20 to define $C_{\mathrm{g}}(0)$ in terms of $N_{\mathrm{g}}$ and $C_{\mathrm{s}}(0)$ in terms of $N_{\mathrm{g}}$ and substitute in Eqs. 23 and 24 to obtain

$$
\begin{gathered}
\text { Flow } \frac{\left(e^{\gamma_{g} d_{g}}-1\right)}{D_{e, g} \gamma_{g}^{2} Z_{g} d_{g}}=\operatorname{Area} \frac{N_{g}}{Z_{g} V_{g}} \\
\text { Flow } \frac{\left(1-e^{-\gamma_{s} d_{s}}\right)}{D_{e, s} \gamma_{s}^{2} Z_{s} d_{s}}=\operatorname{Area} \frac{N_{s}}{Z_{s} V_{s}}
\end{gathered}
$$

We combine Eqs. 25 and 26 to obtain a single expression for Flow $w_{D}$ similar to Eq. 24 . This process yields an expression for $Y_{\mathrm{gs}}$.

$$
Y_{g S}=\left\lceil\frac{e^{\gamma_{g} d_{g}}-1}{D_{e, g} \gamma_{g}^{2} Z_{g} d_{g}}-\frac{1-e^{-\gamma_{s} d_{s}}}{D_{e, s} \gamma_{s}^{2} Z_{s} d_{s}}\right\rceil^{1}
$$

In the last layer of a series, we use

$$
Y_{u-o u t}=\left\lceil\frac{D_{e, u} \gamma_{u}^{2} Z_{u} d_{u}}{e^{\gamma_{u} d_{u}}-1}\right\rfloor
$$


By a similar flow-matching process, we obtain equivalent expressions for advection flow, Flow $_{A}$, in mol s-1, at compartment interfaces. The analytical solution for $\mathrm{Flow}_{A}$ is

$$
\text { Flow }=\text { Area } \times v_{e, g} \times C_{g}\left(d_{g}\right)=\text { Area } \times v_{e, g} \times C_{g}(0) e^{-\gamma_{g} d_{g}}
$$

Substituting for $C_{\mathrm{g}}(0)$ in terms of $N_{\mathrm{g}}$ from Eq. 20 gives,

$$
\text { Flow }_{A}=\frac{v_{e, g} \gamma_{g} N_{g}}{\left(e^{\gamma_{g} d_{g}}-1\right)}
$$

By summing Flow $_{D}$ and $F l o w_{A}$, we obtain an expression for overall flow from $\mathrm{g}$ to $\mathrm{s}$, Flow $=$ Flow $_{D}+$ Flow $_{A}$. By recognizing that $V_{i}=d_{i} \times$ Area, and by comparing the combination of Eqs. 24 and 30 to the expression below,

$$
\text { Flow }=\left(T_{\mathrm{gs}} N_{\mathrm{g}}-T_{\mathrm{sg}} N_{\mathrm{s}}\right)=\left\{\left(T_{\mathrm{gs}} Z_{\mathrm{g}} V_{\mathrm{g}}\right) f_{\mathrm{g}}-\left(T_{\mathrm{sg}} Z_{\mathrm{s}} V_{\mathrm{s}}\right) f_{\mathrm{s}}\right\}
$$

we obtain expressions for the inventory-based transfer terms $T_{\mathrm{gs}}$ and $T_{\mathrm{sg}}$ as well as equivalent fugacity-based transfer factors. We provide these results in Table 3 . The equations in Table 3 apply when the depth of the soil compartments are defined such that the condition $d_{u} \gamma_{u} \leq d_{l} \gamma_{l}$ holds.

\section{RESULTS}

Because models are developed for specific purposes, they are not "true" or "valid" in a general sense, but become useful by accumulating confidence through a series of steps including calibration, verification, and validation or evaluation. Thus, the primary goal of this section is explain the process we used to calibrate, verify, and evaluate the proposed multi-layer soil compartment model. We organize our presentation of results into three issues-comparison of the steady- 
state and transient compartment model results to the analytical model results, model applications, and model limitations.

\section{Calibration and Verification with the Analytical Solution}

Steady-State Solutions

In order to verify that the compartment system matches the analytical solution from a standard advection-dispersion-reaction model, we compare both concentration and cumulative contaminant mass obtained from these two approaches. This is shown in Figure 3, where both quantities are shown in terms of normalized depth. Results from both a three- and four-compartment model are shown. The stair-step shapes shown in Figure 3(a) reveal that, in contrast to the continuous concentration profile of the analytical solution, the compartment models provide only discrete concentrations. These concentrations track the analytical solution and we obtain improved resolution with more compartments. In Figure 3(b) we compare the cumulative inventory predicted by the three- and fourcompartment models to that predicted by the analytical solution. Here we see a very good match, with the four-compartment model providing an almost exact tracking of the analytical solution and the three compartment model showing a slight underestimation in the lowest soil compartment. More compartments can be added to further improve resolution.

\section{Transient Solutions}

Because we calibrate the soil compartment to match the steady-state analytical solution, we must consider how well this approximation works under transient conditions. Even though a complete evaluation of this issue is beyond the scope of 
this paper, we made a preliminary investigation of the model performance under transient conditions. Under transient conditions we transform the steady-state mass balance Eqs. 10 through 13 into the corresponding dynamic equations,

$$
\begin{aligned}
& \frac{d N_{a}}{d t}=-\left(T_{a g}+k_{a}\right) N_{a}+S_{a}+T_{g a} N_{g} \\
& \left.\frac{d N_{g}}{d t}=-\left(T_{g a}+T_{g s}+k_{g}\right) N_{g}+T_{a g} N_{a}+T_{s g} N_{s} \quad \text { \{Ground-surface SOIL }\right\} \\
& \frac{d N_{s}}{d t}=-\left(T_{s g}+T_{s v}+k_{s}\right) N_{s}+T_{g s} N_{g}+T_{v s} N_{v} \quad\{\text { Root-zone SOIL }\} \\
& \left.\frac{N_{v}}{d t}=-\left(T_{v s}+k_{v}\right) N_{v}+T_{s v} N_{s} \quad \text { \{Deeper vadose SOIL }\right\}
\end{aligned}
$$

We solved Eqs. 32-35 using the Stella software (42) and the same boundary conditions defined for Eq. 1 . At $t=0$, we set $\mathrm{N}_{\mathrm{g}}=\mathrm{N}_{\mathrm{s}}=\mathrm{N}_{\mathrm{v}}=0$ and impose a continuous source term $S_{a}$ that maintains the concentration at the surface of soil layer at $C_{g}(t)=$ $\mathrm{N}_{\mathrm{g}} / \mathrm{V}_{\mathrm{g}}=1$. We used Eq. 3 to obtain a transient concentration by depth. The equivalent compartment inventory was obtained from the analytical solution by numerically integrating Eq. 3. In Figure 4 we compare the compartment and analytical solution during a transient simulations. The upper diagram (a) compares the compartment model results and analytical solution of soil-layer inventories versus normalized time and the lower diagram (b) plots the relative error of the compartment model results and analytical solution versus normalized time. Here 
we note that a good match is obtained from the compartment algorithms well before steady state conditions arise.

\section{Model Applications}

We carried out case studies with five substances that have significantly different behaviors in soil. These are benzene, benzo(a)pyrene (BaP), methyl-tertbutylether (MTBE), 2,3,7,8-tetrachorlodibenzo(p)dioxin (TCDD), and tritium as tritiated water. Benzene is released to the environment from gasoline and other combustion processes, and is not expected to penetrate deeply into soil layers because of its low water solubility, partitioning to soil organic material, and relatively rapid degradation (43). $\mathrm{BaP}$ is a polycyclic aromatic compound produced in combustion. It has a very low vapor pressure, high organic-carbon partitioning, and moderate degradation rates in soils. MTBE has been used widely as a gasoline additive to reduce emissions of carbon monoxide and hydrocarbons from vehicles. Most of the MTBE that is emitted into the atmosphere is destroyed by oxidation; however, a small percentage has been found to enter the ground water from air, indicating that it penetrates several meters under the soil surface (14). This penetration is attributable to MTBE's high solubility and resistance to degradation in soil. TCDD is released into the environment from industrial activities, hazardous waste, hospital and municipal solid-waste incineration, forest fires, and residential wood burning (44). Although primarily released to air in urban regions, dioxin is found in soils throughout the northern hemisphere as it readily partitions into soil and has a relatively long transport distance in the environment (45). Tritium is a radioactive form of hydrogen. Since tritium behaves like hydrogen chemically, it is usually found attached to water molecules in place of hydrogen. With a half-life of 12.3 years and its ability to move with water, we expect tritium to penetrate deeply into soil. We selected tritium for the case study in part because we had access to a site with a long- 
term (10-20 year) continuous releases to air along with multimedia environmental samples including soil layers and ground water (46).

Table 4 summarizes the chemical properties we used to characterize these chemicals for soil penetration models along with the resulting Damkoehler depth and Peclet number. We see here significant variations in the Damkoehler depth, which we consider the measure of soil penetration potential. More interesting though is that two substances, benzene and TCDD have the same penetration depth but for different reasons. Benzene, with a Peclet number of 0.1 , moves through soil mainly by dispersion/diffusion, but also by advection. Its short half-life accounts for its shallow penetration. In contrast TCDD, with a Peclet number of 0.0002 , moves through soil only by dispersion/diffusion. Because of its long half life, the shallow penetration of TCDD is accounted for by its low mobility. For three of the compounds, TCDD, MTBE, and tritium, we have plotted in Figure 5 concentration versus depth using the both the analytical solution and the compartment model representation. Also shown are values that represent observations reported in other studies. For TCDD we use the observation that in core samples from around the globe collected following 50 years of release, $60 \%$ of the observed TCDD mass is in the top $15 \mathrm{~cm}$ of the soil cores $(47,48)$. For MTBE the model results are compared to the results reported by Pankow et al. (14). The tritium results come from an environmental assessment at Lawrence Berkeley National Laboratory (46). These results reveal that what differs from compound to compound is the scale of the penetration profile and not the shape of the profile. These results support the premise that the critical first step for multimedia models (whether simple box models, analytical models, or complex numerical simulations) is to determine the correct scaling for penetration into soil. 


\section{Model Capabilities and Limitations}

We tested the compartment model both for its ability to replicate the steadystate analytical solution and its performance across a wide range of input values. We anticipated that performance would degrade at the extremes of advection- and dispersion-dominated transport or for compounds with long half lives. We were particularly concerned that the compartment approximation would break down in advection-dominated regimes, that is, situations with a high Peclet number ${ }^{1}$. Contrary to our expectations, we found that, with the use of Damkoehler scaling, the compartment model performs exactly as illustrated in Figure 3 over a very broad range of chemical properties and landscape conditions. We have tested the model with $\mathrm{K}_{\mathrm{ow}}$ ranging from 0.01 to $10^{7}$, with $\mathrm{K}_{\mathrm{aw}}$ ranging from $10^{-6}$ to 1000 , with the $\mathrm{v}_{\text {water }}$ (soil-water percolation) ranging from 0 to $0.3 \mathrm{~m} / \mathrm{d}$, and with soil transformation half-lives ranging from 0.1 to $10^{5}$ day. This range of parameter values has resulted in Peclet numbers from 0 to $10^{9}$. Yet, with the Damkoehler normalization, we have seen no deviation from the performance illustrated in Figure 3 across these parameter values ranges.

\section{DISCUSSION}

Based on Damkoehler-depth scaling, we construct compartment models that replicate with high reliability the flux and mass distribution obtained from the exact analytical solution of the differential equations describing the dispersion, advection, and transformation of chemicals. But unlike the analytical solution, which requires fixed boundary conditions and uniform conditions within the soil column, a small number of soil compartments can capture vertical heterogeneity and be dynamically linked to other compartments (air, vegetation, ground water, surface water) in multimedia fate models. The Damkoehler depth guides the structuring of the soil

\footnotetext{
${ }^{1}$ The Peclet number is calculated as $\mathrm{v}_{\mathrm{e}} \mathrm{Z}^{*} / \mathrm{D}_{\mathrm{e}}$ and expresses the ratio transport by advection to transport by diffusion.
} 
compartments in multimedia models for both single soil layers and multiple soil layers, enabling the user to properly account for the amount of soil likely to interact with the air, and thus determines the correct storage volume of the soil. For models that use only one soil layer, the work here suggests that one obtains optimum model performance with available data by making use of Damkoehler depth to structure models or interpret field measurements. However, we found it optimum to use at least two soil layers and to use a thin surface soil layer to properly account for the air-soil mass-transfer coefficient.

We present a novel approach for determining the mass based transfer factors between soil layers. This type of system is appropriate for use in multimedia models, where transfer factors are developed to explain the fate and transport of a chemical among multiple components of the environment. This is especially true if multiple simulations need to be completed to evaluate the uncertainty and variability in the environment. By providing a self-consistent process by which chemical transport in soils can be normalized by a characteristic scale, our approach removes much of the guesswork and many of the assumptions that have to date been required for setting up soil compartments in multimedia models.

\section{ACKNOWLEDGEMENTS}

This work was supported in part by the US Environmental Protection Agency National Exposure Research Laboratory through Interagency Agreement \# DW-98838190-01-0 and carried out at Lawrence Berkeley National Laboratory through the US Department of Energy under Contract Grant No. DE-AC03-76SF00098. 
Table 1. Definitions of fugacity capacities and partition coefficients used in the soil compartment model. ${ }^{\mathrm{a}, \mathrm{b}}$

\begin{tabular}{|c|c|c|c|}
\hline Name & Symbol & Formula or value & Units \\
\hline Fugacity capacity of gas phase & $Z_{\text {air }}$ & $=1 /(\mathrm{RT})$ & $\mathrm{mol} /\left(\mathrm{m}^{3}-\mathrm{Pa}\right)$ \\
\hline $\begin{array}{l}\text { Fugacity capacity of substances } \\
\text { dissolved in water }\end{array}$ & $Z_{\text {water }}$ & $=1 / \mathrm{H}$ & $\mathrm{mol} /\left(\mathrm{m}^{3}-\mathrm{Pa}\right)$ \\
\hline Fugacity capacity of air particles ${ }^{c}$ & $\mathrm{Z}_{\mathrm{ap}}$ & $=0.00123 \mathrm{~K}_{\mathrm{oa}} \mathrm{f}_{\mathrm{om}} \mathrm{Z}_{\mathrm{air}} \rho_{\mathrm{ap}}$ & $\mathrm{mol} /\left(\mathrm{m}^{3}-\mathrm{Pa}\right)$ \\
\hline Fugacity capacity of soil solids & $Z_{\mathrm{sp}}$ & $=0.001 \mathrm{~K}_{\mathrm{d}} \rho_{\mathrm{sp}} \mathrm{Z}_{\text {water }}$ & $\mathrm{mol} /\left(\mathrm{m}^{3}-\mathrm{Pa}\right)$ \\
\hline $\begin{array}{l}\text { Fugacity capacity of bulk air } \\
\text { (gases and particles) }\end{array}$ & $\mathrm{Z}_{\mathrm{a}}$ & $=\mathrm{Z}_{\mathrm{air}}+\left(\mathrm{PC} / \rho_{\mathrm{ap}}\right) \mathrm{Z}_{\mathrm{ap}}$ & $\mathrm{mol} /\left(\mathrm{m}^{3}-\mathrm{Pa}\right)$ \\
\hline $\begin{array}{l}\text { Fugacity capacity of soil } \\
\text { compartment } \mathrm{i} \text {, for the three- } \\
\text { compartment example: } \\
\qquad \begin{array}{l}\mathrm{i}=\mathrm{g} \text { for ground surface } \\
\mathrm{i}=\mathrm{s} \text { for root zone } \\
\mathrm{i}=\mathrm{v} \text { for vadose } \\
\text { etc. }\end{array}\end{array}$ & $\mathrm{Z}_{\mathrm{i}}$ & $\begin{aligned}= & \alpha_{i} Z_{\text {air }}+\beta_{i} Z_{\text {water }} \\
& +\left(1-\alpha_{i}-\beta_{i}\right) Z_{s p}\end{aligned}$ & $\mathrm{~mol} /\left(\mathrm{m}^{3}-\mathrm{Pa}\right)$ \\
\hline Octanol/air partition coefficient & $\mathrm{K}_{\mathrm{oa}}$ & $=\mathrm{K}_{\mathrm{ow}} / \mathrm{H}$ & $\begin{array}{l}\mathrm{m}^{3} \text { (air)/ } \\
\mathrm{m}^{3} \text { (octanol) }\end{array}$ \\
\hline $\begin{array}{l}\text { Soil distribution coefficient } \\
\text { (solid/water concentration ratio) }\end{array}$ & $\mathrm{K}_{\mathrm{d}}$ & $=0.48 \mathrm{~K}_{\mathrm{ow}} \mathrm{f}_{\mathrm{oc}}$ & $\begin{array}{l}\mathrm{L} \text { (water)/ } \\
\mathrm{kg} \text { (soil solids) }\end{array}$ \\
\hline $\begin{array}{l}\text { Octanol/water partition } \\
\text { coefficient }\end{array}$ & $\mathrm{K}_{\mathrm{ow}}$ & Literature citations & $\begin{array}{l}\mathrm{L}(\text { water }) / \\
\mathrm{L} \text { (octanol) }\end{array}$ \\
\hline
\end{tabular}

aUnless otherwise noted these definitions are from reference (4) but some of the notations are different.

bSee Table 2 for definitions of parameters other than $\mathrm{Z}$ values and partition coefficients

cHarner et al. (40) 
Table 2. Definitions and values of compartment properties ${ }^{a}$

\begin{tabular}{|c|c|c|c|}
\hline Name & Symbol & Formula or value & Units \\
\hline Density of air particles $b$ & $\rho_{\mathrm{ap}}$ & 1000 & $\mathrm{~kg} \mathrm{~m}^{-3}$ \\
\hline Concentration of particles in air & $P C$ & $5.0 \times 10^{-8}$ & $\mathrm{~kg} \mathrm{~m}^{-3}$ \\
\hline $\begin{array}{l}\text { Fraction organic matter in air } \\
\text { particles b }\end{array}$ & $\mathrm{f}_{\mathrm{om}}$ & 0.4 & no units \\
\hline $\begin{array}{l}\text { Long-term average deposition } \\
\text { velocity (wet and dry) of air } \\
\text { particles to soil }\end{array}$ & $\mathrm{V}_{\mathrm{d}}$ & 0.0046 & $\mathrm{~m} \mathrm{~s}^{-1}$ \\
\hline Long-term average rainfall & rain & $\begin{array}{l}3.2 \times 10^{-8} \\
(0.32)\end{array}$ & $\begin{array}{c}\mathrm{m} \mathrm{s}^{-1} \\
\left(\mathrm{~cm} \mathrm{~d}^{-1}\right)\end{array}$ \\
\hline $\begin{array}{l}\text { Thickness of equivalent } \\
\text { diffusion boundary layer in } \\
\text { air above the surface soil }\end{array}$ & $\delta_{a}$ & 0.05 & $\mathrm{~m}$ \\
\hline Density of soil particles & $\rho_{\mathrm{sp}}$ & 2600 & $\mathrm{~kg} \mathrm{~m}^{-3}$ \\
\hline Volume fraction of soil that is gas & $\alpha_{i}$ & 0.2 & no units \\
\hline $\begin{array}{l}\text { Volume fraction of soil that is } \\
\text { liquid }\end{array}$ & $\beta_{\mathrm{i}}$ & 0.3 & no units \\
\hline $\begin{array}{l}\text { Volume fraction of soil that is } \\
\text { solid }\end{array}$ & $\left(1-\alpha_{i}-\beta_{i}\right)$ & 0.5 & no units \\
\hline Fraction of organic carbon in soil & $\mathrm{f}_{\mathrm{OC}}$ & 0.02 & no units \\
\hline $\begin{array}{l}\text { Equivalent diffusion coefficient } \\
\text { for bioturbation }{ }^{c}\end{array}$ & $D_{\text {bio }}$ & $\begin{array}{c}2 \times 10^{-10} \\
\left(3 \times 10^{-11} \text { to } 1 \times 10^{-9}\right)\end{array}$ & $\mathrm{m}^{2} \mathrm{~s}^{-1}$ \\
\hline
\end{tabular}

a Unless noted otherwise these values are based on ranges of these parameters provided by McKone et al. (49)

bRiley et al. (50)

c Cousins et al. $(24,36)$ 
Table 3. Summary of the mass-inventory and fugacity-based transfer factors for the soil layer compartment model.

\begin{tabular}{|c|c|c|}
\hline Transfer & $\begin{array}{l}\text { Mass-Inventory Based System Transfer } \\
\text { Factor }\end{array}$ & Fugacity Based System Transfer Factor \\
\hline $\begin{array}{l}\text { Air to } \\
\text { ground- } \\
\text { surface soil }\end{array}$ & $\begin{array}{c}\boldsymbol{T}_{\mathbf{a g}}= \\
\frac{1}{Z_{a} \times d_{a}} \times\left(Y_{a g}+V_{d} \frac{P C}{\rho_{p}} Z_{a p}+\text { rain } \times Z_{\text {water }}\right)\end{array}$ & $\begin{array}{c}Z_{a} V_{a} T_{\mathbf{a g}}= \\
\operatorname{Areax}\left(Y_{a g}+V_{d} \frac{P C}{\rho_{p}} Z_{a p}+\text { rain } \times Z_{\text {water }}\right)\end{array}$ \\
\hline $\begin{array}{l}\text { Ground- } \\
\text { surface soil } \\
\text { to air }\end{array}$ & $\begin{array}{c}\boldsymbol{T}_{\mathbf{g a}}=\frac{Y_{a g}}{Z_{g} \times d_{g}}, \\
Y_{a g}=\left\lceil\frac{1}{Z_{a i \gamma} U_{a}}+\frac{1}{Z_{g} U_{g}}\right\rceil^{-1}\end{array}$ & $Z_{\mathrm{g}} V_{\mathrm{g}} T_{\mathrm{ga}}=\operatorname{Area} \times Y_{a g}$ \\
\hline $\begin{array}{l}\text { Fugacity- } \\
\text { based mass- } \\
\text { transfer } \\
\text { coefficient } \\
\text { from g to s }\end{array}$ & & $\boldsymbol{r}_{\mathbf{s g}}=\left\lceil\frac{e^{\gamma_{g} d_{g}}-1}{D_{e, g} \gamma_{g}^{2} Z_{g} d_{g}}-\frac{1-e^{-\gamma_{s} d_{s}}}{D_{e, s} \gamma_{s}^{2} Z_{s} d_{s}}\right\rceil^{1}$ \\
\hline $\begin{array}{l}\text { Transfer from } \\
\text { surface soil } \\
\text { to root soil }\end{array}$ & $T_{\mathbf{g s}}=\frac{Y_{g s}}{Z_{g} d_{g}}+\frac{v_{e, g} \gamma_{g}}{\left(e^{\gamma_{g} d_{g}}-1\right)}$ & $Z_{\mathbf{g}} V_{\mathbf{g}} T_{\mathbf{g s}}=\operatorname{Areax}\left\lfloor Y_{g s}+\frac{v_{e, g} \gamma_{g} Z_{g} d_{g}}{\left(e^{\gamma_{g} d_{g}}-1\right)}\right\rfloor$ \\
\hline $\begin{array}{l}\text { Transfer from } \\
\text { root soil to } \\
\text { surface soil }\end{array}$ & $T_{\text {sg }}=\frac{Y_{g s}}{Z_{s} d_{s}}$ & $Z_{s} V_{s} T_{s g}=A r e a x Y_{g s}$ \\
\hline \multicolumn{3}{|c|}{ Generalized Relationship between any two upper (u) and lower (1) soil layers } \\
\hline $\begin{array}{l}\text { Fugacity- } \\
\text { based mass- } \\
\text { transfer } \\
\text { coefficient } \\
\text { from } u \text { to } 1\end{array}$ & & $Y_{\mathbf{u l}}=\left\lceil\frac{e^{\gamma_{u} d_{u}}-1}{D_{e, u} \gamma_{u}^{2} Z_{u} d_{u}}-\frac{1-e^{-\gamma_{l} d_{l}}}{D_{e, l} \gamma_{l}^{2} Z_{l} d_{l}}\right\rceil^{1}$ \\
\hline $\begin{array}{l}\text { Transfer from } \\
\text { u to } 1\end{array}$ & $T_{\mathbf{u l}}=\frac{Y_{u l}}{Z_{u} d_{u}}+\frac{v_{e, u} \gamma_{u}}{\left(e^{\gamma_{u} d_{u}}-1\right)}$ & $\left.Z_{\mathbf{u}} V_{\mathbf{u}} \boldsymbol{T}_{\mathbf{u} \mathbf{l}}=\operatorname{Area\alpha } \mid Y_{u l}+\frac{v_{e, u} \gamma_{u} Z_{u} d_{u}}{\left(e^{\gamma_{u} d_{u}}-1\right)}\right\rfloor$ \\
\hline $\begin{array}{l}\text { Transfer from } \\
1 \text { to } u\end{array}$ & $T_{1 \mathbf{u}}=\frac{Y_{u l}}{Z_{l} d_{l}}$ & $Z_{1} V_{1} T_{1 u}=A r e a \times Y_{u l}$ \\
\hline
\end{tabular}


Table 4 Chemical properties and derived properties for chemicals used in the case studies $^{a}$

\begin{tabular}{|c|c|c|c|c|c|}
\hline Property & Tritiumb,c & $\begin{array}{l}2,3,7,8- \\
\text { TCDD }\end{array}$ & MTBE & $\begin{array}{l}\text { Benzo(a)- } \\
\text { pyrene }\end{array}$ & Benzene \\
\hline $\begin{array}{l}\text { Molecular weight } \\
\qquad(\mathrm{g} / \mathrm{mol})\end{array}$ & 20.0 & 322 & 88.0 & 252 & 78.1 \\
\hline $\mathrm{K}_{\mathrm{ow}}$ & 0.042 & $4.6 \times 10^{6}$ & 8.71 & $2.2 \times 10^{6}$ & 151 \\
\hline $\begin{array}{l}\text { Henry's law constant } \\
\qquad\left(\mathrm{Pa}-\mathrm{m}^{3} / \mathrm{mol}\right)\end{array}$ & 0.057 & 2.5 & 70.3 & 0.092 & 574 \\
\hline $\mathrm{K}_{\mathrm{aw}}$ & $2.3 \times 10^{-5}$ & 0.00105 & 0.03 & $3.9 \times 10^{-5}$ & 0.24 \\
\hline $\begin{array}{l}\text { Half-life in surface } \\
\text { soil (d) }\end{array}$ & 4508 & 4000 & 400 & 450 & 50 \\
\hline $\begin{array}{l}\text { Damkoehler } \\
\text { depth }(m)\end{array}$ & 17 & 0.30 & 1.5 & 0.1 & 0.3 \\
\hline Peclet number & 343 & 0.00027 & 3.7 & 0.00018 & 0.1 \\
\hline
\end{tabular}

cUnless noted otherwise these values are based on ranges of these parameters developed for the CalTOX database and used by Hertwich et al. (6).

bAs tritiated water, THO.

${ }^{c}$ Chemical properties for tritiated water are from Reference (46). 


\section{Figure Captions}

Figure 1. Concentration curves at various non-dimensional times plotted against a non-dimensionalized depth scale

Figure 2. Comparison of the heterogeneous structure of an "actual" soil layer and the more idealized set of porous layers that are used in soil compartment models.

Figure 3. For the compartment-model solution and analytical solution, the upper diagram (a) compares the concentration versus non-dimensional (Damkoehler normalized) depth and the lower diagram (b) compares cumulative inventory to the normalized depth $\mathrm{z} / \mathrm{z}^{*}$.

Figure 4. For the compartment-model approximation and analytical solution during a transient simulation, the upper diagram (a) compares the box model and analytical results for compartment inventories as a function of normalized time and the lower diagram (b) plots the ratio of the compartment model results to the analytical results as function of normalized time.

Figure 5. Results of the model applications for three compounds showing a similar concentration profile with depth but a significantly different scale. 


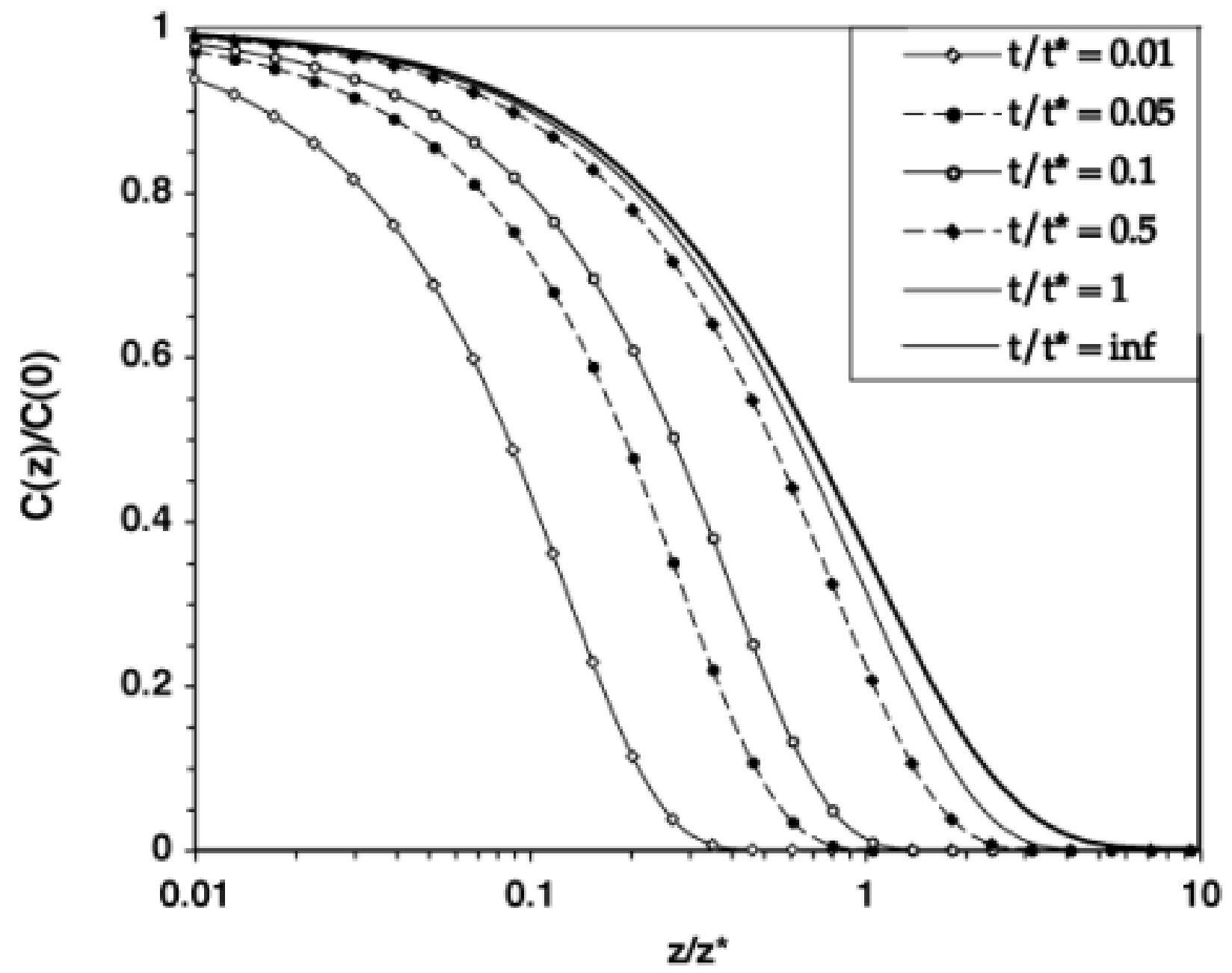

Figure 1 


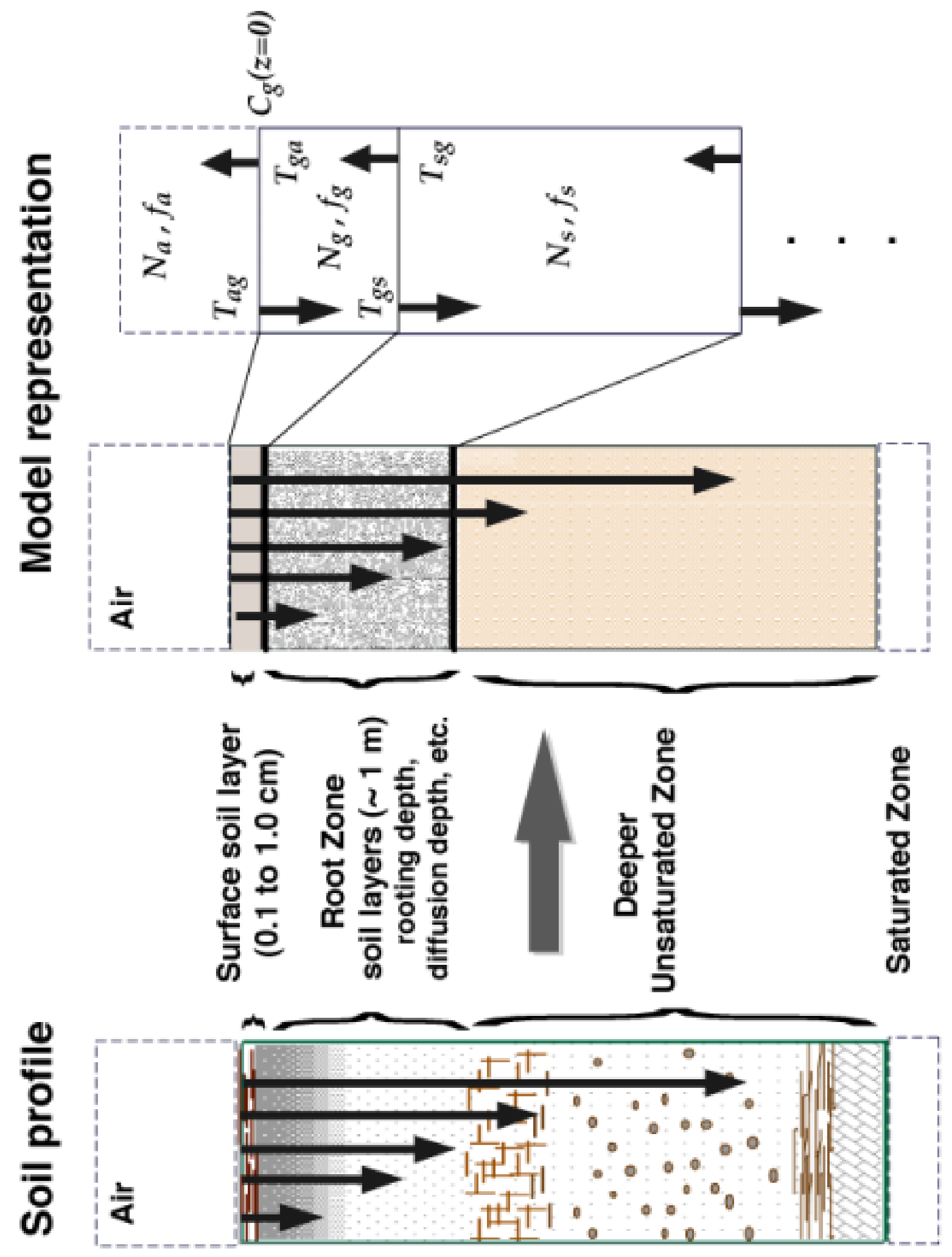

Figure 2 
Figure 3(a)

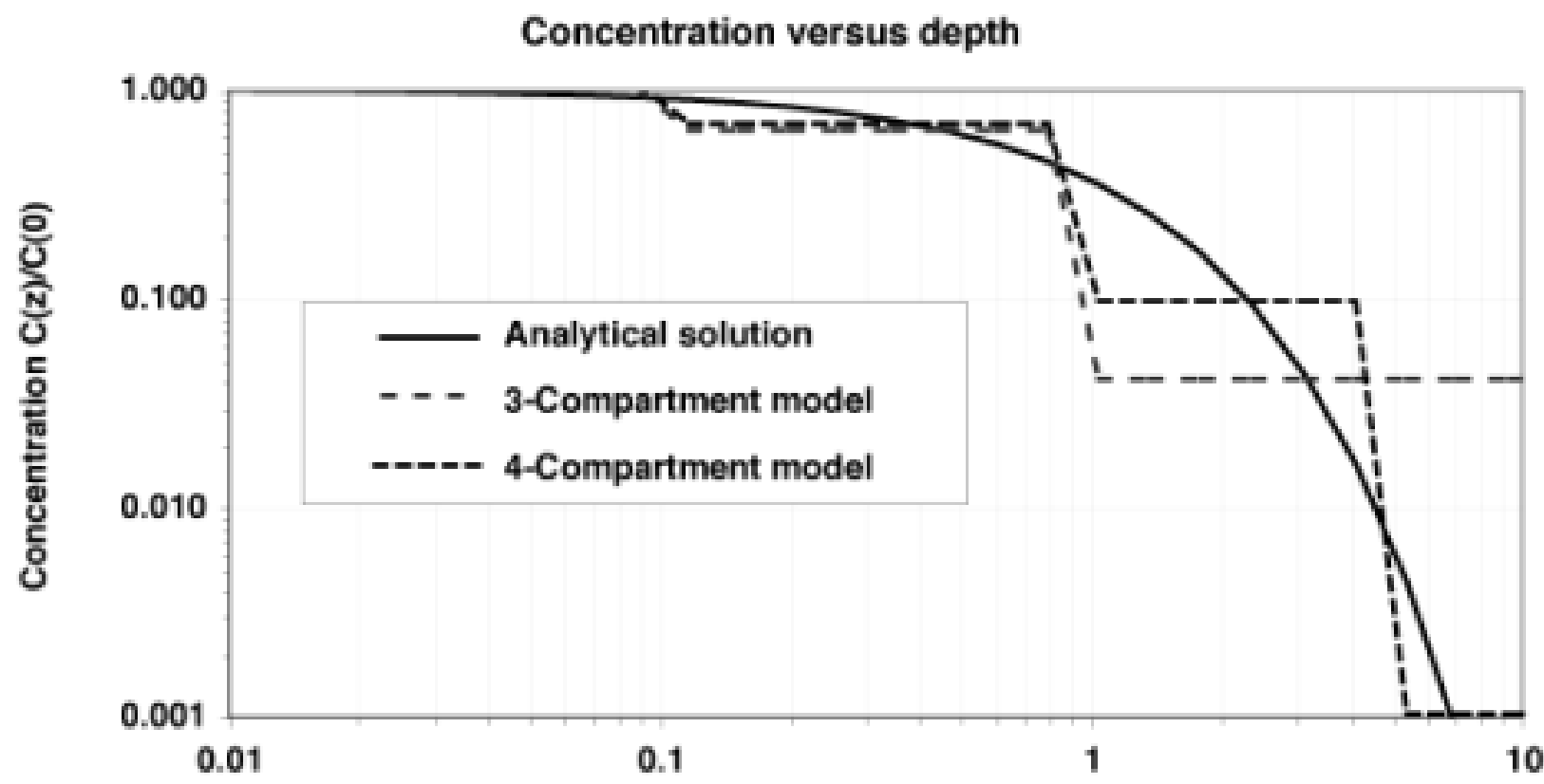

Figure 3(b)

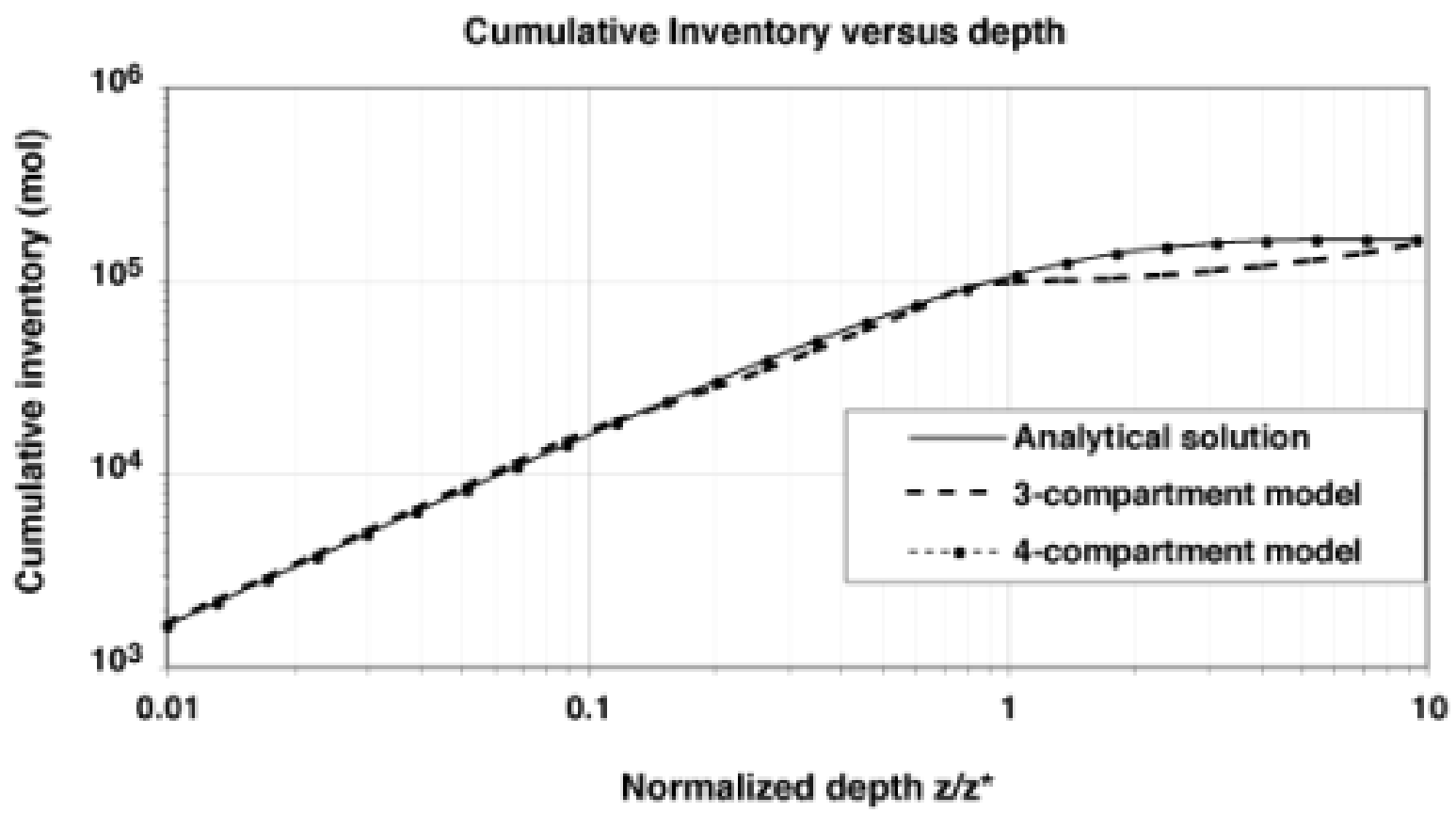

Figure 3 
Figure 4(a)

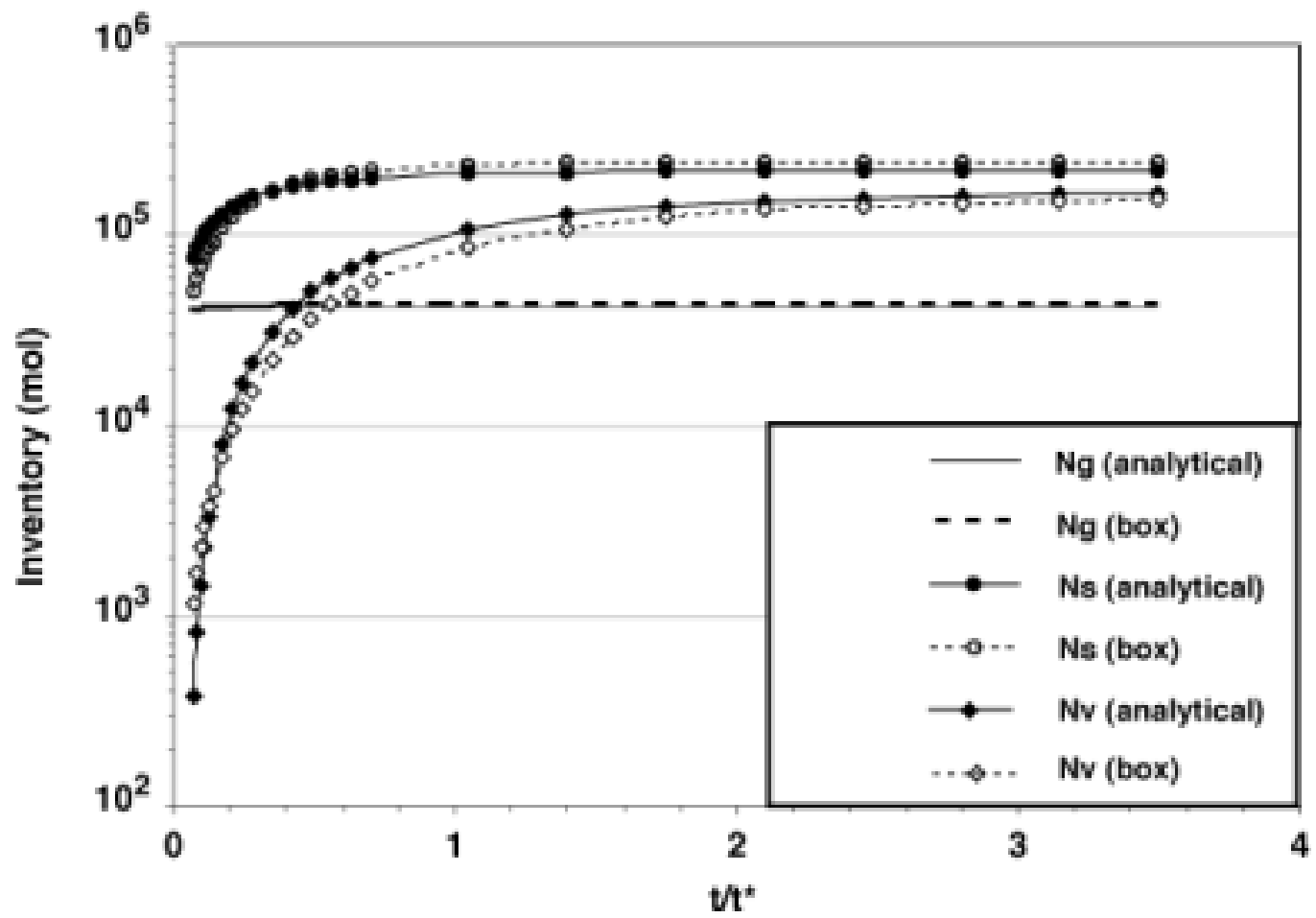

Figure 4(b)

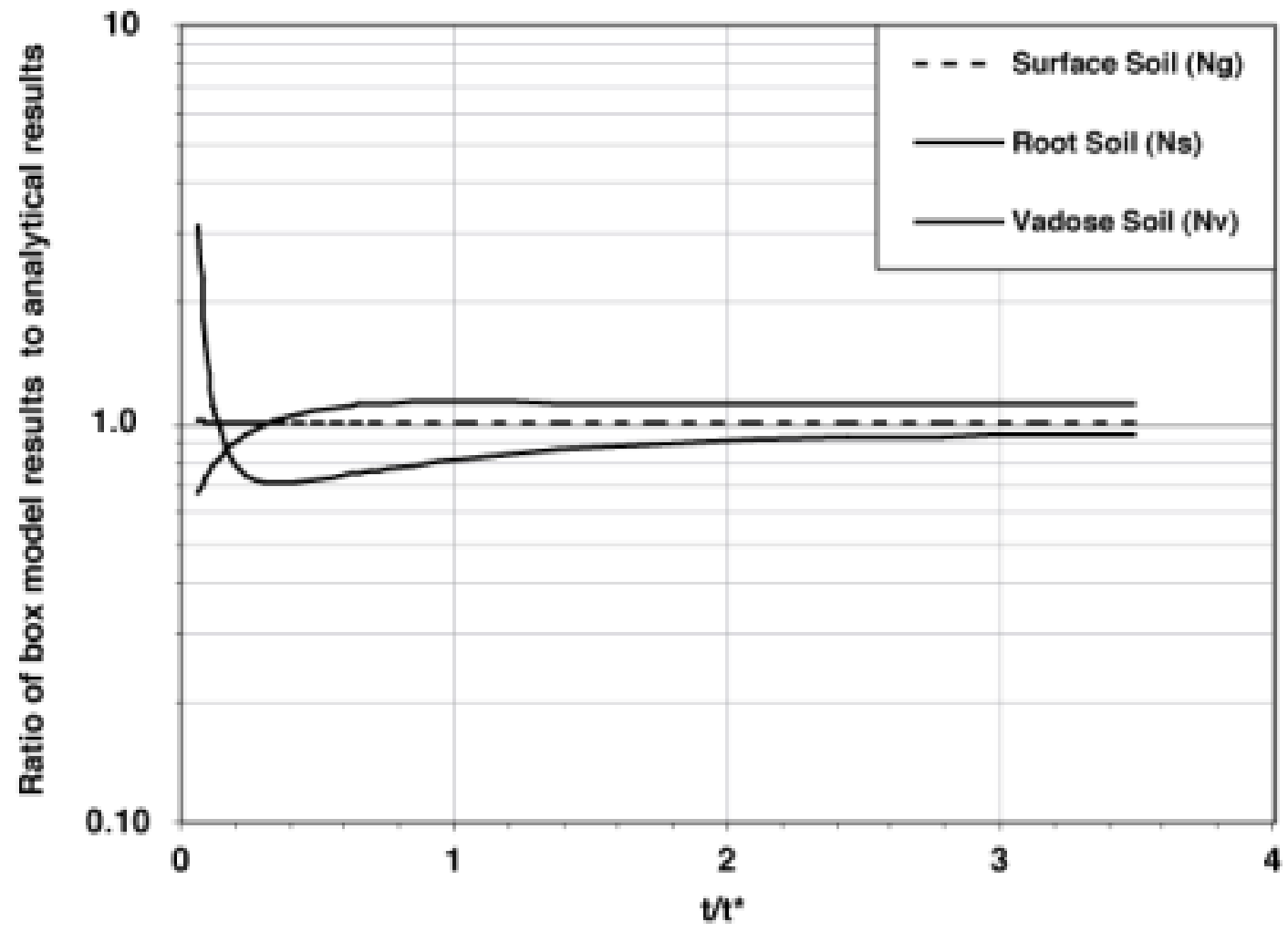

Figure 4 


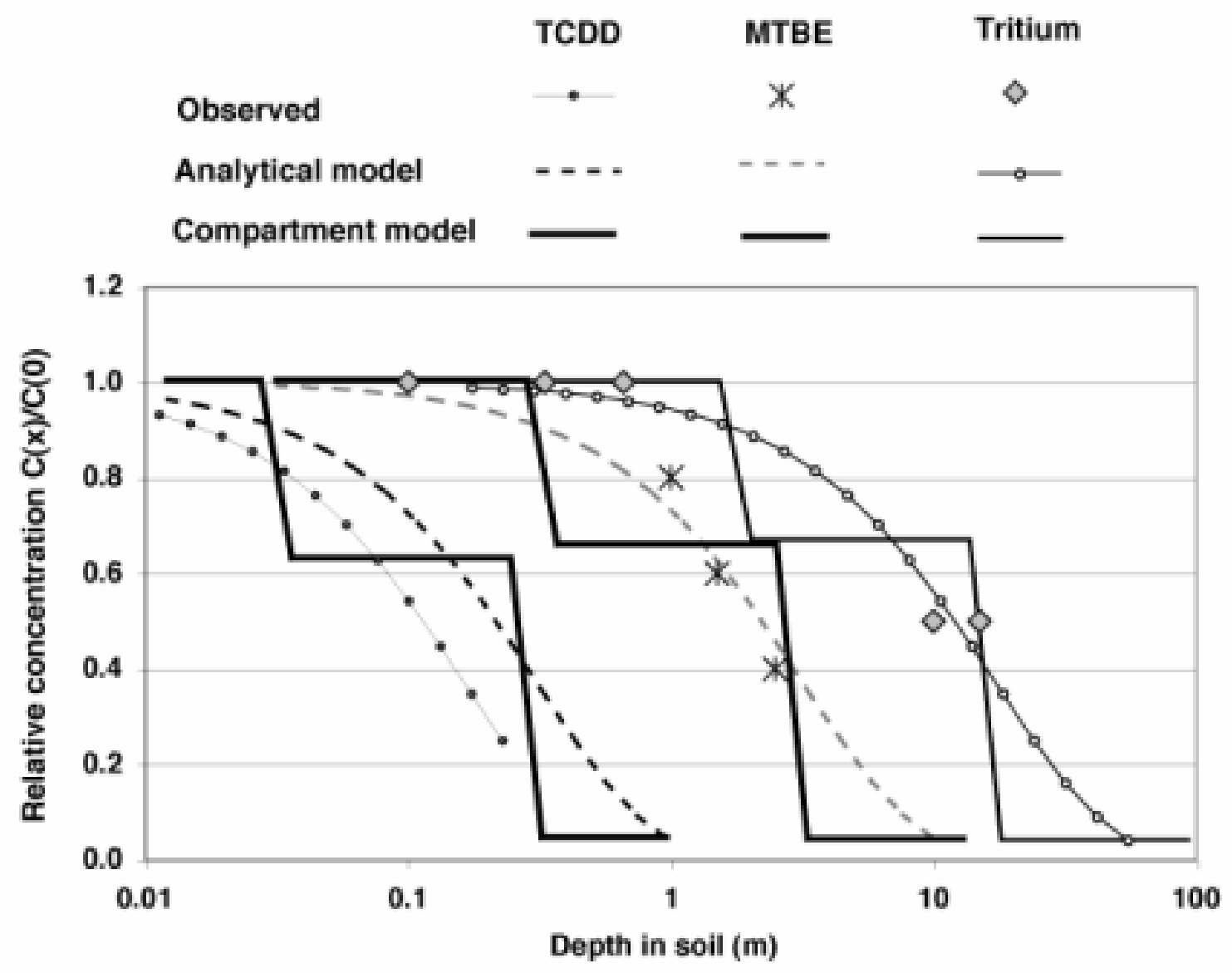

Figure 5 


\section{REFERENCES}

(1) Mackay, D.; Patterson, S. Environmental Science E Technology 1991, 25, 427-436.

(2) McKone, T. E. CalTOX, A Multimedia Total-Exposure Model for HazardousWastes Sites Part I: Executive Summary; Lawrence Livermore National Laboratory: Livermore, CA, 1993

(3) Cowan, C. E.; Mackay, D.; Feijtel, T. C. J.; Van De Meent, D.; Di Guardo, A.; Davies, J.; Mackay, N. The Multi-Media Fate Model: A Vital Tool for Predicting the Fate of Chemicals; SETAC Press: Pensacola, FL, 1995.

(4) Mackay, D. Multimedia Environmental Models, The Fugacity Approach, 2nd Edition ed.; Lewis Publishers: Chelsea, MI, 2001.

(5) Cowan, C. E.; Versteeg, D. J.; Larson, R. J.; Kloepper-Sams, P. J. Regulatory Toxicology and Pharmacology 1995, 21, 3-31.

(6) Hertwich, E. G.; Mateles, S. F.; Pease, W. S.; McKone, T. E. Environmental Toxicology and Chemistry 2001, 20, 928-939.

(7) Huijbregts, M. A. J.; Guinee, J. B.; Reijnders, L. Chemosphere 2001, 44, 59-65.

(8) MacLeod, M.; Woodfine, D. G.; Mackay, D.; McKone, T.; Bennett, D.; Maddalena, R. Environmental Science and Pollution Research 2001, 8, 156-163.

(9) Jury, W. A.; Spencer, W. F.; Farmer, W. J. J. of Environmental Quality 1983, 12, 558-564.

(10) Mendoza, C. A.; Frind, E. O. Water Resources Research 1990, 26, 379-387.

(11) Ho, C. K.; Udell, K. S. Heat Transfer in Geophysical Media 1991, 172, 55-62.

(12) Tseng, P. H.; Jury, W. A. Water Resources Research 1994, 30, 2051-2063.

(13) Wang, D.; Knuteson, J. A.; Yates, S. R. Journal of Environmental Quality 2000, $29,639-644$. 
(14) Pankow, J. F.; Thomson, N. R.; Johnson, R. L.; Baehr, A. L.; Zogorski, J. S. Environmental Science \& Technology 1997, 31, 2821-2828.

(15) Wania, F., D. Mackay Science of the Total Environment 1995, 160/161, 211-232.

(16) Scheringer, M. Environmental Science \& Technology 1996, 30, 2660-2660.

(17) Bennett, D. H.; McKone, T. E.; Matthies, M.; Kastenberg, W. E. Environmental Science \& Technology 1998, 32, 4023-4030.

(18) Priemer, D. A.; Diamond, M. L. Environmental Science and Technology 2002, Web version.

(19) USEPA TRIM Total Risk Integrated Methodology Status Report; US Enivronmental Protection Agency Office of Air Quality Planning and Standards: Research Triangle Park, 1999

(20) Anderson, T. A.; Beauchamp, J. J.; Walton, B. T. J. of Environmental Quality 1991, 424, 420-424.

(21) Thibodeaux, L. J. Chemodynamics, Environmental Movement of Chemicals in Air, Water, and Soil; John Wiley and Sons: New York, 1979.

(22) Jury, W. A. International Crop Science I 1993, 96, 91-96.

(23) Mullerlemans, H.; Vandorp, F. Journal of Environmental Radioactivity 1996, 31, 7-20.

(24) Cousins, I. T.; Mackay, D.; Jones, K. C. Chemosphere 1999, 39, 2519-2534.

(25) Thibodeaux, L. J. H., S.T. Environ. Progress 1983, 1, $42-46$.

(26) Jury, W. A.; Scotter, D. R. Soil Science Society of America Journal 1994, 1336, 58 p1327-1336.

(27) van de Meent, D. SIMPLEBOX: A Generic Multimedia Fate Evaluation Model; National Institute of Public Health and Environmental Protection (RIVM), Bilthoven, The Netherlands, 1996 
(28) McKone, T. E. CalTOX, A Multimedia Total-Exposure Model for HazardousWastes Sites Part III: The Multiple-Pathway Exposure Model; Lawrence Livermore National Laboratory: Livermore CA, 1993

(29) Cohen, Y.; Tsai, W. T.; Chetty, S. L.; Mayer, G. J. Environmental Science E Technology 1990, 24, 1549-1558.

(30) Jury, W. A.; Russo, D.; Streile, G.; Elabd, H. Water Resources Research 1990, 26, 13-20.

(31) Whicker, F. W.; Kirchner, T. B. Health Physics 1987, 52, 717-737.

(32) McKone, T. E. Reliability Engineering and Systems Safety 1996, 54, 165-181.

(33) USDA Analytical Solutions of the One-Dimensional Convective-Dispersive Solute Transport Equation; U.S. Dept. of Agriculture, Agricultural Research Service: Washington, D.C, 1982

(34) Millington, R. J.; Quirk, J. M. Transactions Faraday Society 1961, 57, 1200-1207.

(35) Moldrup, P., Olesen, T., Yamaguchi, T., Schjonning, P., and Rolston, D.E. Soil Science 1999, 164, 542-551.

(36) Cousins, I. T.; Gevao, B.; Jones, K. C. Chemosphere 1999, 39, 2507-2518.

(37) Cousins, I. T.; Mackay, D. Chemosphere 2001, 44, 643-654.

(38) Batterman, S.; Padmanabham, I.; Milne, P. Environmental Science and Technology 1996, 30, 770-778.

(39) Ho, C. K.; K, S. U. Contaminant Hydrology 1992, 316, 291-316.

(40) Harner, T.; Mackay, D.; Jones, K. C. Environmental Science \& Technology 1995, $29,1200-1209$.

(41) Lindhart, B. C. T. H. A. L. Water, Air and Soil Pollution 1996, 89, 129-146.

(42) High-Performance-Systems STELLA 7.0.1, High Performance Systems: East Lyme, New Hampshire, 2001; 
(43) Day, M. J.; Reinke, R. F.; Thomson, J. A. M. Environmental Forensics 2001, 2, 2128.

(44) USEPA Exposure and Human Health Reassessment of 2,3,7,8Tetrachlorodibenzo-p-Dioxin (TCDD) and Related Compounds (DRAFT); US Environmental Protection Agency: Washington DC, 2001

(45) Eisenberg, J. N. S.; Bennett, D. H.; McKone, T. E. Environmental Science \& Technology 1998, 32, 115-123.

(46) McKone, T. E., Brand, K.P., and Shan, C Environmental Health Risk Assessment for Tritium Releases at the National Tritium Labeling Facility at Lawrence Berkeley National Laboratory; Lawrence Berkeley National Laboratory: Berkeley, 1997

(47) Brzuzy, L. P.; Hites, R. A. Environmental Science \& Technology 1995, 29, 20902098.

(48) Brzuzy, L. P.; Hites, R. A. Environmental Science E Technology 1996, 30, 17971804.

(49) McKone, T. E.; Bodnar, A. B.; Hertwich, E. G. Development and Evaluation of State-Specific Landscape Data Sets for Life-Cycle Impact Assessment; Lawrence Berkeley National Laboratory: Berkeley, California, 1999

(50) Riley, W. J.; McKone, T. E.; Lai, A. C. K.; Nazaroff, W. W. Environmental Science \& Technology 2002, 36, 200-207. 